\title{
Reverse 'hot cross bun', 'Mercedes-Benz', 'face of the giant panda and her cub' signs with pontine infarcts: a radiological pandora
}

\author{
Rajendra Singh Jain, Raghavendra Bakki Sannegowda, Rahul Jain, Swayam Prakash
}

Department of Neurology, SMS Medical College, Jaipur, Rajasthan, India

\section{Correspondence to}

Professor Rajendra Singh Jain, drrsjain@yahoo.com

Accepted 26 August 2014
CrossMark

To cite: Jain $R S_{\text {, }}$ Sannegowda RB, Jain $\mathrm{R}$ et al. BMJ Case Rep Published online: [please include Day Month Year] doi:10.1136/bcr-2013203447

\section{DESCRIPTION}

Though uncommon, bilateral middle cerebellar peduncle (MCP) hyperintensities have been reported following pontine infarcts, in Wilson disease (WD) and due to other aetiologies. ${ }^{1}$ In WD, the 'face of the giant panda' sign, internal capsule hyperintensities and rarely the 'face of the panda cub' sign due to pontine hyperintensities at the opening of the cerebral aqueduct into the fourth ventricle is described. ${ }^{2}$ The 'hot cross bun' (HCB) sign is seen in multisystem atrophy, spinocerebellar ataxia and rarely in cerebrotendinous xanthomatosis. ${ }^{3}$ We report a case of a hypertensive man with recurrent, sudden onset, cranial nerve palsies (third and lower motor neuron seventh nerves) followed by complete recovery without any cognitive or movement disorder manifestations. Workup for the WD and vasculitis was negative. CT angiography of the brain, including neck vessels, was normal. MRI of the brain showed bilateral MCP hyperintensities with pontine infarcts (figure 1A). Interestingly, MRI also showed multiple radiological signs. Though the HCB sign is described due to cruciform hyperintensity in the pons resulting from the degeneration of pontine neurons and loss of myelinated transverse fibres with preserved tegmentum and corticospinal tracts, ${ }^{3}$ in our patient there was cruciform hypointensity quadrisecting the pontine hyperintensities to suggest a reverse HCB sign (figure 1B) along with bilateral internal capsule hyperintensities (figure 1C). Our patient also had a 'face of the

\section{Learning points}

- Though hyperintensities trisecting the pons lead to the 'Mercedes-Benz' sign, a quadrisection of the pons can lead to a 'hot cross bun' sign.

- Cruciform hyperintensities usually cause a 'hot cross bun' sign, but cruciform hypointensities may result in a reverse 'hot cross bun' sign.

- A 'panda and her cub' sign along with a 'Mercedes-Benz' sign, though rare, can be seen in a non-Wilsonian patient.

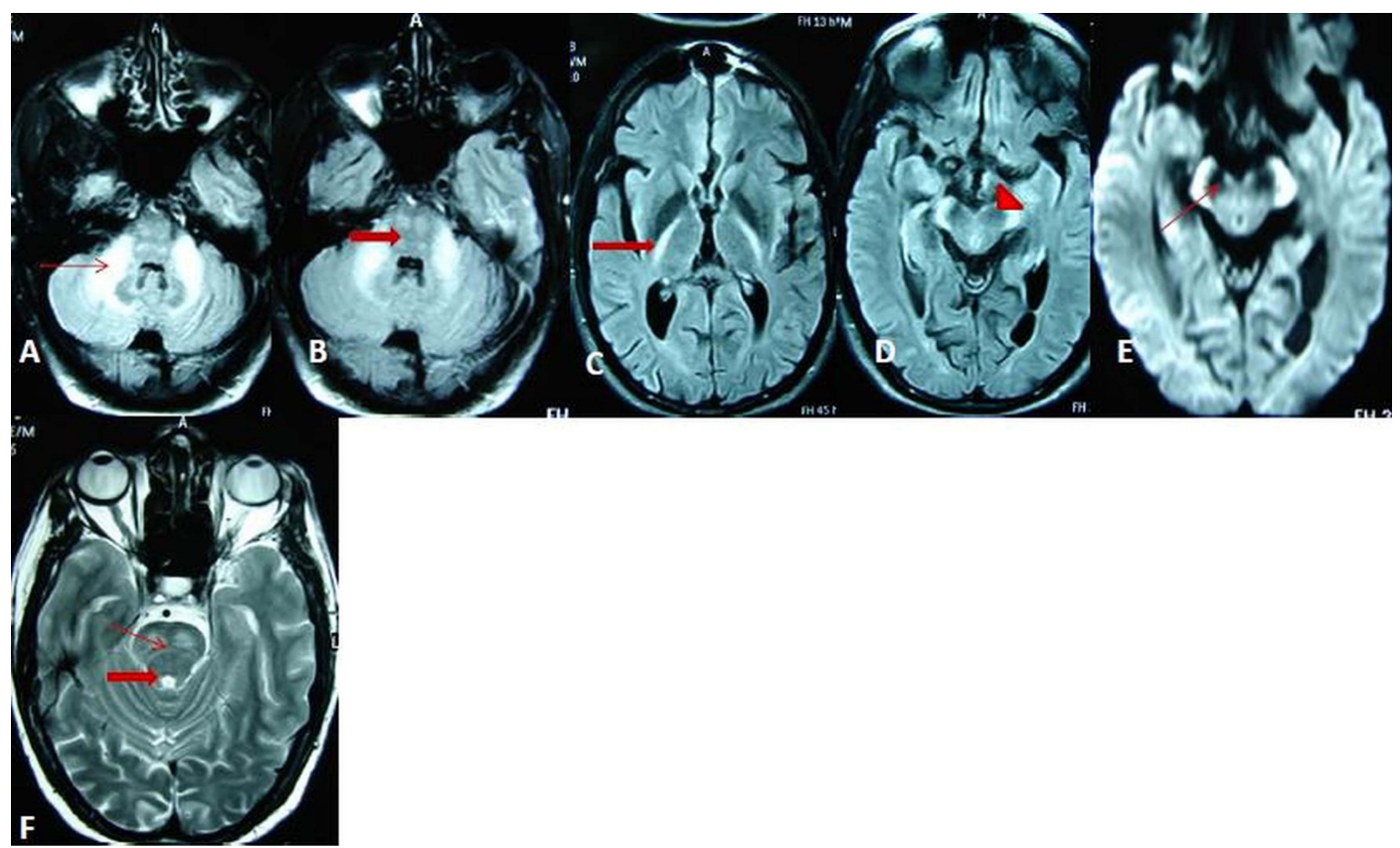

Figure 1 T2 fluid-attenuated inversion recovery axial MRI showing (A) symmetrical middle cerebellar peduncle hyperintensities (thin arrow), (B) pontine hyperintensities quadrisected by a cruciform hypointense line making a 'hot cross bun' (reverse) sign in the pons (thick arrow) (C) bilateral hyperintensities in the posterior limb of the internal capsule (thick arrow) (D) 'face of the giant panda'. Diffusion weighted image showing (E) the 'face of the giant panda'. T2-weighted MRI showing (F) hyperintensities in the pons at the aqueductal opening into the fourth ventricle giving an appearance of the 'face of the panda cub' (thick arrow) and pontine 'Mercedes-Benz' sign (thin arrow). 
giant panda and her cub' sign (figure 1D-F) along with the 'Mercedes-Benz' sign (figure 1F). All these signs in a non-Wilsonian patient have not been described so far in the literature, and therefore the association with bilateral MCP hyperintensity and reverse HCB sign further adds to its rarity.

Contributors All authors contributed in preparing the manuscript, analysis, data interpretation and providing intellectual input.

Competing interests None.

Patient consent Obtained.
Provenance and peer review Not commissioned; externally peer reviewed.

\section{REFERENCES}

1 Okamoto K, Tokiguchi S, Furusawa T, et al. MR features of diseases involving bilateral middle cerebellar peduncles. AJNR Am J Neuroradiol 2003;24;1946-54.

2 Shivakumar R, Thomas SV. Face of the giant panda and her cub: MRI correlates of Wilson disease. Neurology 2009;72:e50.

3 Jain RS, Sannegowda RB, Agrawal A, et al. 'Hot cross bun' sign in a case of cerebrotendinous xanthomatosis: a rare neuroimaging observation. BMJ Case Rep 2013;2013:pii:bcr2012006641.

Copyright 2014 BMJ Publishing Group. All rights reserved. For permission to reuse any of this content visit http://group.bmj.com/group/rights-licensing/permissions.

BMJ Case Report Fellows may re-use this article for personal use and teaching without any further permission.

Become a Fellow of BMJ Case Reports today and you can:

- Submit as many cases as you like

- Enjoy fast sympathetic peer review and rapid publication of accepted articles

- Access all the published articles

- Re-use any of the published material for personal use and teaching without further permission

For information on Institutional Fellowships contact consortiasales@bmjgroup.com

Visit casereports.bmj.com for more articles like this and to become a Fellow 